\title{
ВИДОВОЕ РАЗНООБРАЗИЕ МИНЕРАЛОВ СУПЕРГРУППЫ ПИРОХЛОРА В КОВДОРСКОМ ФОСКОРИТ-КАРБОНАТИТОВОМ КОМПЛЕКСЕ
}

Коноплева Н.Г. ${ }^{1}$, Яковенчук В.Н. ${ }^{2}$, Калашников А.О. ${ }^{2}$, Пахомовский Я.А. ${ }^{2}$, Базай А.В. 2 , Паникоровский Т.Л. ${ }^{1}$, Михайлова Ю.А. ${ }^{2}$

${ }^{1}$ Центр наноматериаловедения КНЦ РАН, Anamumbl, konoplyova55@mail.ru

${ }^{2}$ Геологический институт КНЦ РАН, Апатить

Общая формула минералов супергруппы пирохлора $-\boldsymbol{A}_{2-m} \boldsymbol{B}_{2} \boldsymbol{X}_{6-w} \boldsymbol{Y}_{1-n .}$ Их номенклатура [5] основана на соотношении ионов в позициях $\boldsymbol{A}, \boldsymbol{B}$ и $\boldsymbol{Y}$. Позицию $\boldsymbol{B}$ занимают $\mathbf{T a}, \mathbf{N b}, \mathbf{T i}, \mathbf{S} \mathbf{b}^{5+}, \mathbf{W}$, a также $\mathrm{V}^{5+}, \mathrm{Sn}^{4+}, \mathrm{Zr}, \mathrm{Hf}, \mathrm{Fe}^{3+}, \mathrm{Mg}, \mathrm{Al}$ и $\mathrm{Si}$. Исходя из пропорции доминирующих атомов в позиции $\boldsymbol{B}$ в супергруппе пирохлора выделяют группы: пирохлора $\left(M^{5+}>M^{4+}\right.$ и $M^{5+}>M^{6+}$ при доминировании $\mathbf{N b}$ среди катионов $\left.M^{5+}\right)$, микролита $\left(M^{5+}>M^{4+}\right.$ и $M^{5+}>M^{6+}$ при доминировании Та среди катионов $\left.M^{5+}\right)$, ромеита $\left(M^{5+}>M^{4+}\right.$ и $M^{5+}>M^{6+}$ при доминировании $\mathbf{S b}$ среди катионов $\left.M^{5+}\right)$, бетафита $\left(M^{4+}\right.$ $>M^{5+}$ и $M^{4+}>M^{6+}$ при доминировании $\mathbf{T i}$ среди катионов $\left.M^{4+}\right)$ и эльсмореита $\left(M^{6+}>M^{4+}\right.$ и $M^{6+}>M^{5+}$ при доминировании $\mathbf{W}$ среди катионов $M^{6+}$ ). Дальнейшая классификация минеральных видов в каждой из перечисленных групп проводится по соотношению ионов в позициях $\boldsymbol{A}$ и $\boldsymbol{Y}$. Позиция $\boldsymbol{Y}$ обычно занята анионами $(\mathbf{O H}, \mathbf{F}, \mathbf{O})$, но также может быть вакантной или занятой $\mathbf{H}_{2} \mathbf{O}$ и крупными одновалентными катионами $(\mathrm{K}, \mathrm{Cs}, \mathrm{Rb})$. Доминирующий в позиции $\boldsymbol{Y}$ компонент определяет первый префикс в названии минерального вида (OH - гидрокси, $\mathrm{F}$ - фтор, $\mathrm{O}$ - окси, - кено, $\mathrm{H}_{2} \mathrm{O}$ - гидро). Позицию $\boldsymbol{A}$ могут занимать катионы $\mathbf{N a}, \mathbf{C a}, \mathbf{P b}^{2+}, \mathbf{S n}^{2+}, \mathbf{S b}^{3+}, \mathbf{Y}, \mathbf{U}, \mathrm{Sr}, \mathrm{Ba}, \mathrm{Fe}^{2+}, \mathrm{Ag}, \mathrm{Mn}, \mathrm{Bi}^{3+}, R E E$, $\mathrm{Sc}, \mathrm{Th}, \mathbf{H}_{2} \mathbf{O}$, или же она может быть частично вакантной. Доминирующий в позиции $\boldsymbol{A}$ компонент (с учетом валентных групп аналогично позиции В) определяет второй префикс в названии минерального вида (Ca - кальцио, $\mathrm{Na}$ - натро, - кено, $\mathrm{Pb}$ - плюмбо, $\mathrm{H}_{2} \mathrm{O}$ - гидро и т.д.). Для позиции $\boldsymbol{X}$ характерен $\mathbf{O}$, но могут также присутствовать $\mathrm{OH}$ и $\mathrm{F}$.

Минералы супергруппы пирохлора являются обычными акцессорными минералами всех типов фоскоритов и карбонатитов Ковдорского массива [2-4, 6-8]. При проведении объёмного минералогического картирования магнетит-апатит-бадделеитового месторождения мы отобрали 540 образцов керна в интервале абсолютных отметок от -80 до -650 метров [8]. Изготовленные из этих

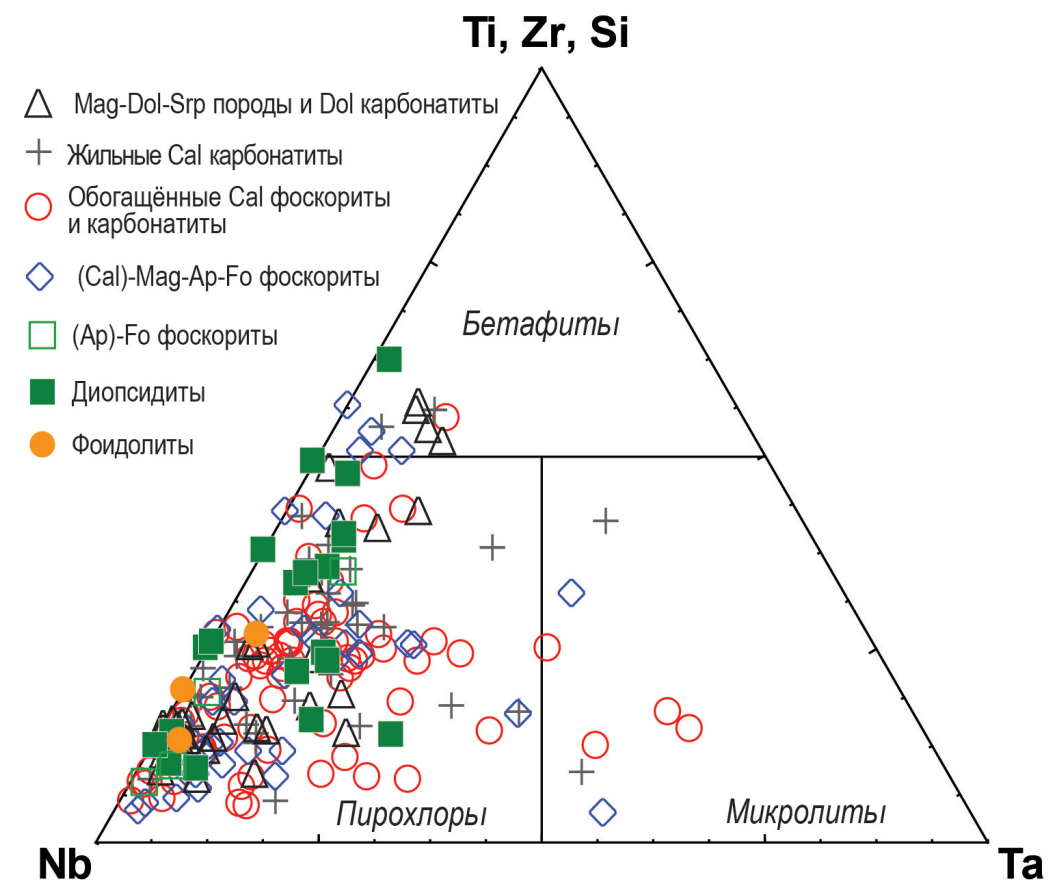

Рис. 1. Классификационная диаграмма минералов супергруппы пирохлора из пород фоскорит-карбонатитового комплекса Ковдорского массива. 
образцов полированные шлифы были изучены при помощи электронного микроскопа LEO-1450 c энергодисперсионным микроанализатором Quantax 200 и волнодисперсионного микроанализатора «Сатеса» MS-46. Полученные данные показали, что подавляющее большинство минералов супергруппы пирохлора представлено собственно пирохлорами, им соответствует около 92 \% из 329 анализов. Микролитам и бетафитам соответствует примерно по 4 \% анализов (рис. 1, табл. 1).

Минералы группы пирохлора встречены во всех типах пород фоскорит-карбонатитового комплекса (рис. 1, 2). Они представлены округлыми, удлинёнными и неправильной формы зёрнами, идиоморфными кубооктаэдрическими и усечёнными октаэдрическими кристаллами, пойкилитовыми и скелетными (мета)кристаллами, микропрожилками и выделениями по трещинкам, оторочками вокруг бадделеита и закономерными срастаниями с ним, частичными псевдоморфозами по бадделеиту и луешиту, реликтами в цирконолите (рис. 3). Из минералов этой группы в ковдорских фоскорит-карбонатитах и вмещающих их фоидолитах и диопсидитах встречены 8 минеральных видов: оксикальциопирохлор (ОСР), оксинатропирохлор (ОNP), гидроксикальциопирохлор (НСР), гидроксинатропирохлор (HNP), гидроксикенопирохлор (НKР), фторкальциопирохлор (FCP), фторнатропирохлор (FNP) и фторкенопирохлор (FKP). Преобладают НCР, HNP и ОСР.

Минералы группы микролита - фторкальциомикролит (FCM), гидроксикальцио-микролит (HCM) и гидроксикеномикролит (HKM) обнаружены в кальцит-магнетит-апатит-(форстеритовых) фоскоритах и жильных кальцитовых карбонатитах (рис. 2). Они представлены обогащёнными танталом зонами в кристаллах пирохлоров или каймами вокруг них, а также вокруг бадделеита; неправильными или округлыми выделениями в магнетите, в ламелях ильменита, в цирконолите или по краю его зёрен (рис. 3). Размер выделений микролитов не превышает 40 мкм.

Минералы группы бетафита - оксикальциобетафит (ОСB) и его катион-дефицитный аналог встречены в фоскоритах и карбонатитах промежуточной и осевой зон рудного тела (рис. 2). Они представлены отдельными зёрнами неправильной, округлой и удлинённой формы, обогащёнными титаном зонами в кристаллах пирохлоров, зонами вокруг кристаллов бадделеита и срастаниями с цирконолитом (рис. 3). Размер выделений - до 85 мкм.

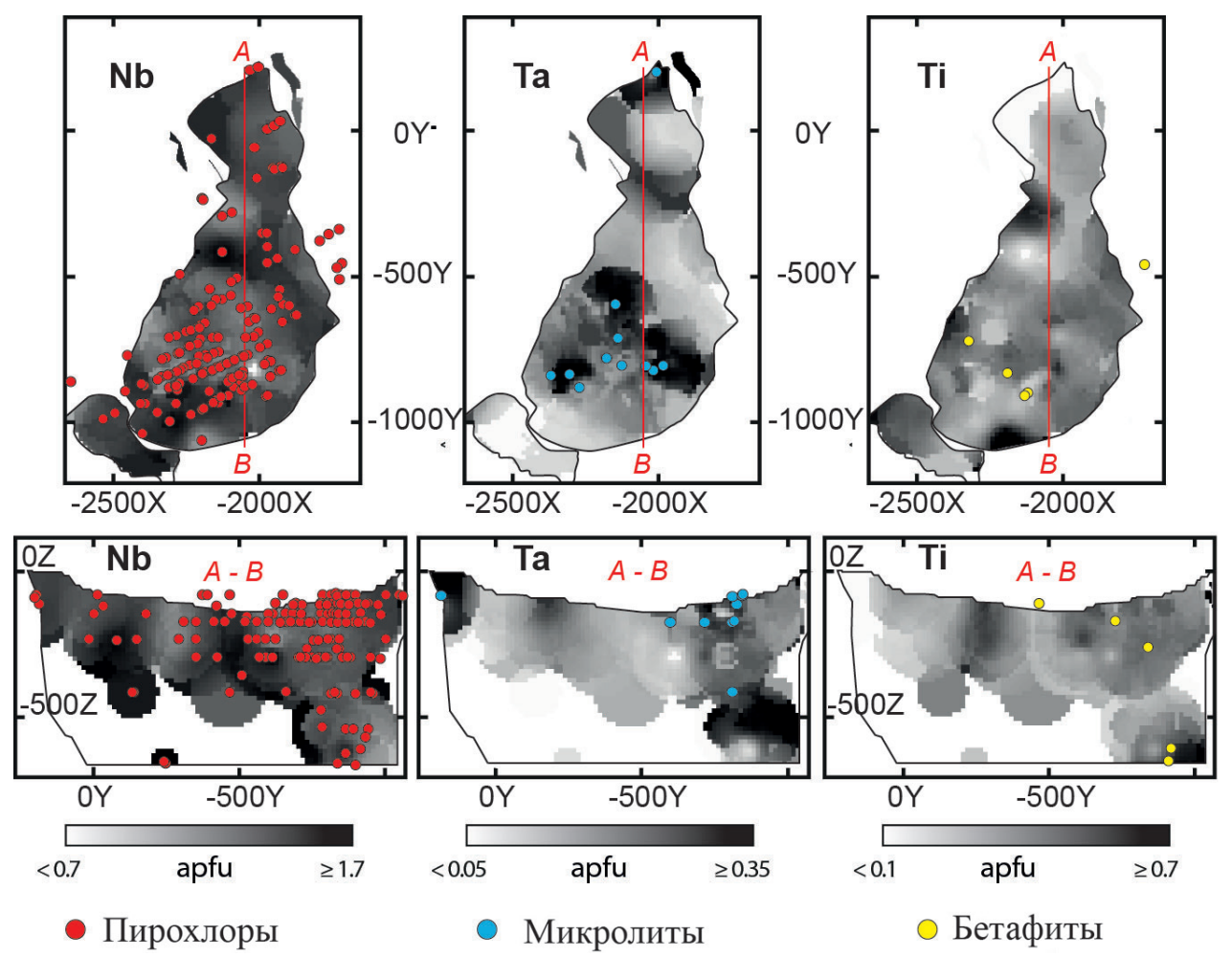

Рис. 2. Изменение содержаний $\mathrm{Nb}$, Та и Ті в минералах супергруппы пирохлора и местоположение пирохлоров, микролитов и бетафитов в фоскорит-карбонатитовом штоке Ковдора. Проекции на горизонт -100 м (вверху) и вертикальный разрез А-В (внизу). 
Таблица 1. Химический состав минералов супергруппы пирохлора (мас. \%) и соответствующие формульные коэффициенты ( $a p f u$ ), рассчитанные на основе $B=2, X=6$ и $Y=1$.

\begin{tabular}{|c|c|c|c|c|c|c|c|c|c|c|c|c|}
\hline Минерал & $\mathrm{OCP}$ & ONP & $\mathrm{HCP}$ & HNP & HKP & FCP & FNP & FKP & $\mathrm{HCM}$ & HKM & $\mathrm{FCM}$ & $\mathrm{OCB}$ \\
\hline F, мас.\% & 1.51 & - & 2.00 & 0.09 & 0.03 & 1.99 & 2.48 & 2.31 & 0.42 & 0.43 & 2.47 & - \\
\hline $\mathrm{Na}_{2} \mathrm{O}$ & 3.59 & 5.12 & 7.31 & 8.03 & 0.89 & 3.45 & 9.90 & - & 0.51 & 0.66 & 3.46 & - \\
\hline $\mathrm{MgO}$ & - & - & - & - & - & - & - & - & - & 0.24 & 0.29 & - \\
\hline $\mathrm{Al}_{2} \mathrm{O}_{3}$ & 0.21 & - & - & - & - & 0.11 & - & - & 0.19 & - & - & - \\
\hline $\mathrm{SiO}_{2}$ & - & 0.19 & - & - & 0.35 & - & - & - & - & 1.62 & - & - \\
\hline $\mathrm{CaO}$ & 13.70 & 8.83 & 15.18 & 10.05 & 8.47 & 15.78 & 8.60 & 8.58 & 9.80 & 4.41 & 11.33 & 12.30 \\
\hline $\mathrm{TiO}_{2}$ & 3.50 & 6.71 & 1.92 & 3.83 & 8.32 & 0.90 & 5.66 & 4.36 & 1.03 & 5.00 & 1.00 & 16.07 \\
\hline $\mathrm{MnO}$ & - & - & - & - & - & - & - & - & - & 0.35 & - & - \\
\hline $\mathrm{Fe}_{2} \mathrm{O}_{3}$ & 2.09 & 1.16 & 0.83 & - & 1.70 & 0.32 & - & 1.62 & 0.50 & 2.23 & 7.01 & 4.60 \\
\hline $\mathrm{ZrO}_{2}$ & - & 1.32 & 0.73 & - & 1.29 & - & - & - & - & 1.09 & 7.68 & - \\
\hline $\mathrm{Nb}_{2} \mathrm{O}_{5}$ & 42.34 & 31.49 & 60.82 & 56.72 & 32.21 & 53.79 & 57.11 & 43.72 & 17.95 & 19.34 & 11.26 & 21.24 \\
\hline $\mathrm{BaO}$ & - & - & - & - & - & - & - & - & - & 7.12 & - & - \\
\hline $\mathrm{La}_{2} \mathrm{O}_{3}$ & - & - & 0.17 & - & - & - & - & - & - & 0.46 & - & 3.59 \\
\hline $\mathrm{Ce}_{2} \mathrm{O}_{3}$ & 1.37 & 0.34 & 1.60 & 3.01 & 0.45 & 2.88 & 2.63 & 1.45 & 0.65 & 3.07 & - & 6.70 \\
\hline $\mathrm{Pr}_{2} \mathrm{O}_{3}$ & - & - & - & - & - & - & - & - & - & 0.51 & - & - \\
\hline $\mathrm{Nd}_{2} \mathrm{O}_{3}$ & 0.41 & 0.13 & 0.11 & - & 0.10 & - & - & - & - & 1.03 & - & - \\
\hline $\mathrm{Ta}_{2} \mathrm{O}_{5}$ & 12.76 & 16.25 & 7.35 & 7.48 & 14.81 & 6.59 & 3.20 & 11.23 & 53.29 & 33.39 & 51.21 & 7.80 \\
\hline $\mathrm{PbO}$ & - & - & - & - & 0.88 & - & - & - & - & - & - & - \\
\hline $\mathrm{ThO}_{2}$ & 14.35 & 1.48 & - & 4.66 & 2.57 & 1.33 & 3.67 & - & 8.09 & 6.11 & - & 22.92 \\
\hline $\mathrm{UO}_{2}$ & 0.45 & 24.64 & - & 3.84 & 20.86 & 0.01 & 4.94 & 26.90 & 5.62 & - & - & - \\
\hline$-\mathrm{O}=\mathrm{F}_{2}$ & 0.64 & - & 0.84 & 0.04 & 0.01 & 0.84 & 1.04 & 0.97 & 0.18 & 0.18 & 1.04 & - \\
\hline$\Sigma$ & 95.64 & 97.67 & 97.18 & 97.67 & 92.91 & 86.31 & 97.16 & 99.20 & 97.86 & 86.86 & 94.66 & 95.22 \\
\hline $\mathrm{Ca}$, apfu & 1.08 & 0.74 & 1.02 & 0.71 & 0.67 & 1.24 & 0.60 & 0.67 & 0.88 & 0.36 & 0.83 & 0.97 \\
\hline $\mathrm{Na}$ & 0.51 & 0.79 & 0.89 & 1.02 & 0.13 & 0.49 & 1.24 & - & 0.08 & 0.10 & 0.46 & - \\
\hline $\mathrm{Ba}$ & - & - & - & - & - & - & - & - & - & 0.21 & - & - \\
\hline $\mathrm{Mn}$ & - & - & - & - & - & - & - & - & - & 0.02 & - & - \\
\hline $\mathrm{La}$ & - & - & - & - & - & - & - & - & - & 0.01 & - & 0.10 \\
\hline $\mathrm{Ce}$ & 0.04 & 0.01 & 0.04 & 0.07 & 0.01 & 0.08 & 0.06 & 0.04 & 0.02 & 0.09 & - & 0.18 \\
\hline $\operatorname{Pr}$ & - & - & - & - & - & - & - & - & - & 0.01 & - & - \\
\hline $\mathrm{Nd}$ & 0.01 & - & - & - & - & - & - & - & - & 0.03 & - & - \\
\hline $\mathrm{Pb}$ & - & - & - & - & 0.02 & - & - & - & - & - & - & - \\
\hline Th & 0.24 & 0.03 & - & 0.07 & 0.04 & 0.02 & 0.05 & - & 0.15 & 0.11 & - & 0.38 \\
\hline $\mathrm{U}$ & 0.01 & 0.43 & - & 0.06 & 0.34 & - & 0.07 & 0.44 & 0.10 & - & - & - \\
\hline $\mathrm{vac}$ & 0.10 & - & 0.05 & 0.07 & 0.79 & 0.17 & - & 0.85 & 0.76 & 1.06 & 0.71 & 0.38 \\
\hline $\mathbf{\Sigma A}$ & 2.00 & 2.00 & 2.00 & 2.00 & 2.00 & 2.00 & 2.02 & 2.00 & 2.00 & 2.00 & 2.00 & 2.00 \\
\hline $\mathrm{Nb}$ & 1.41 & 1.13 & 1.72 & 1.68 & 1.07 & 1.79 & 1.67 & 1.45 & 0.68 & 0.68 & 0.35 & 0.70 \\
\hline $\mathrm{Ta}$ & 0.26 & 0.35 & 0.13 & 0.13 & 0.30 & 0.13 & 0.06 & 0.22 & 1.21 & 0.71 & 0.95 & 0.16 \\
\hline $\mathrm{Ti}$ & 0.19 & 0.40 & 0.09 & 0.19 & 0.46 & 0.05 & 0.27 & 0.24 & 0.06 & 0.29 & 0.05 & 0.89 \\
\hline $\mathrm{Zr}$ & - & 0.05 & 0.02 & - & 0.05 & - & - & - & - & 0.04 & 0.26 & - \\
\hline $\mathrm{Si}$ & - & - & 0.02 & - & 0.03 & - & - & - & - & 0.12 & - & - \\
\hline $\mathrm{Fe}^{3+}$ & 0.12 & 0.07 & 0.04 & - & 0.09 & 0.02 & - & 0.09 & 0.03 & 0.13 & 0.36 & 0.25 \\
\hline $\mathrm{Al}$ & 0.02 & - & - & - & - & 0.01 & - & - & 0.02 & - & - & - \\
\hline $\mathrm{Mg}$ & - & - & - & - & - & - & - & - & - & 0.03 & 0.03 & - \\
\hline
\end{tabular}




\begin{tabular}{|l|c|c|c|c|c|c|c|c|c|c|c|c|}
\hline $\mathbf{\Sigma B}$ & $\mathbf{2 . 0 0}$ & $\mathbf{2 . 0 0}$ & $\mathbf{2 . 0 0}$ & $\mathbf{2 . 0 0}$ & $\mathbf{2 . 0 0}$ & $\mathbf{2 . 0 0}$ & $\mathbf{2 . 0 0}$ & $\mathbf{2 . 0 0}$ & $\mathbf{2 . 0 0}$ & $\mathbf{2 . 0 0}$ & $\mathbf{2 . 0 0}$ & $\mathbf{2 . 0 0}$ \\
\hline$* \mathrm{O}^{2-}$ & 6.00 & 6.00 & 5.86 & 5.94 & 5.36 & 6.00 & 5.83 & 5.80 & 5.74 & 4.24 & 4.00 & 5.91 \\
\hline$*(\mathrm{OH})^{-}$ & - & - & 0.14 & 0.06 & 0.64 & - & 0.17 & 0.20 & 0.26 & 1.76 & 2.00 & 0.09 \\
\hline $\boldsymbol{\Sigma} \mathbf{X}$ & $\mathbf{6 . 0 0}$ & $\mathbf{6 . 0 0}$ & $\mathbf{6 . 0 0}$ & $\mathbf{6 . 0 0}$ & $\mathbf{6 . 0 0}$ & $\mathbf{6 . 0 0}$ & $\mathbf{6 . 0 0}$ & $\mathbf{6 . 0 0}$ & $\mathbf{6 . 0 0}$ & $\mathbf{6 . 0 0}$ & $\mathbf{6 . 0 0}$ & $\mathbf{6 . 0 0}$ \\
\hline${ }^{*} \mathrm{O}^{2-}$ & 0.36 & 0.54 & - & - & - & 0.20 & - & - & & - & - & 0.50 \\
\hline$*(\mathrm{OH})^{-}$ & 0.29 & 0.46 & 0.72 & 0.98 & 0.99 & 0.34 & 0.49 & 0.47 & 0.89 & 0.93 & 0.47 & - \\
\hline $\mathrm{F}^{-}$ & 0.35 & - & 0.28 & 0.02 & 0.01 & 0.46 & 0.51 & 0.53 & 0.11 & 0.07 & 0.53 & - \\
\hline $\boldsymbol{\Sigma}$ & $\mathbf{1 . 0 0}$ & $\mathbf{1 . 0 0}$ & $\mathbf{1 . 0 0}$ & $\mathbf{1 . 0 0}$ & $\mathbf{1 . 0 0}$ & $\mathbf{1 . 0 0}$ & $\mathbf{1 . 0 0}$ & $\mathbf{1 . 0 0}$ & $\mathbf{1 . 0 0}$ & $\mathbf{1 . 0 0}$ & $\mathbf{1 . 0 0}$ & $\mathbf{0 . 5 0}$ \\
\hline
\end{tabular}

*Расчётные значения. Прочерк - содержание ниже предела обнаружения.
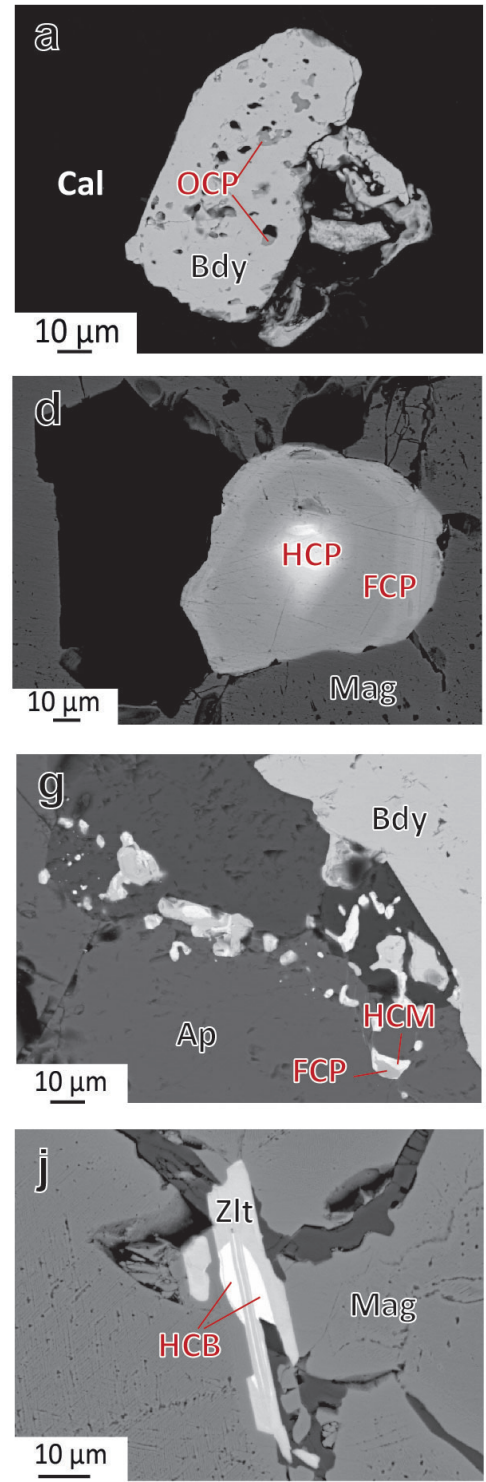
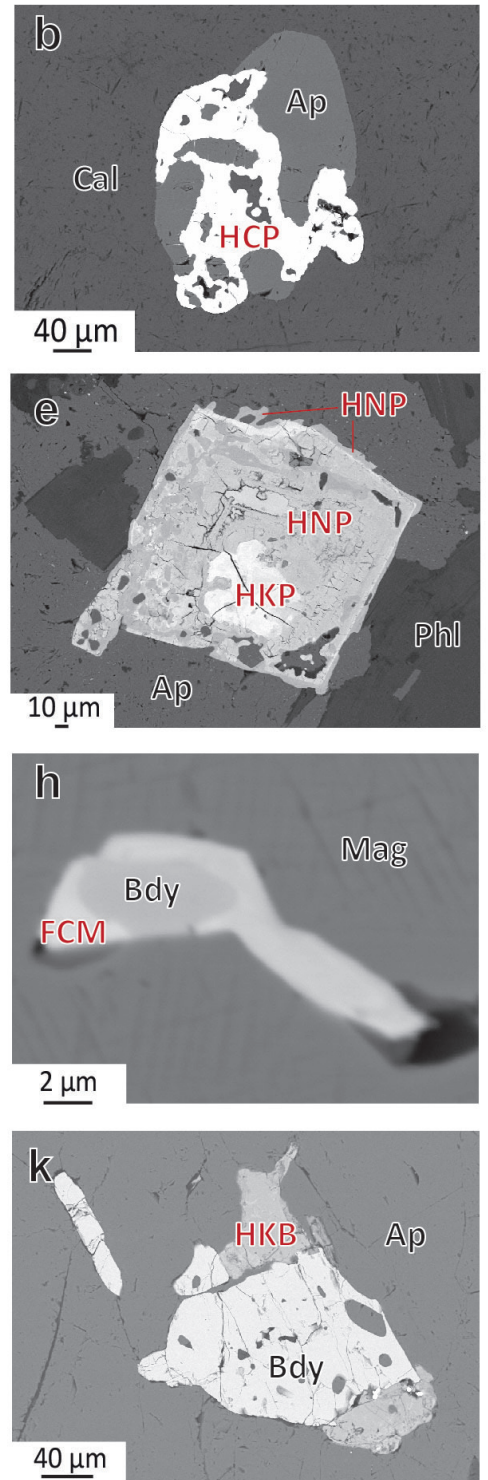
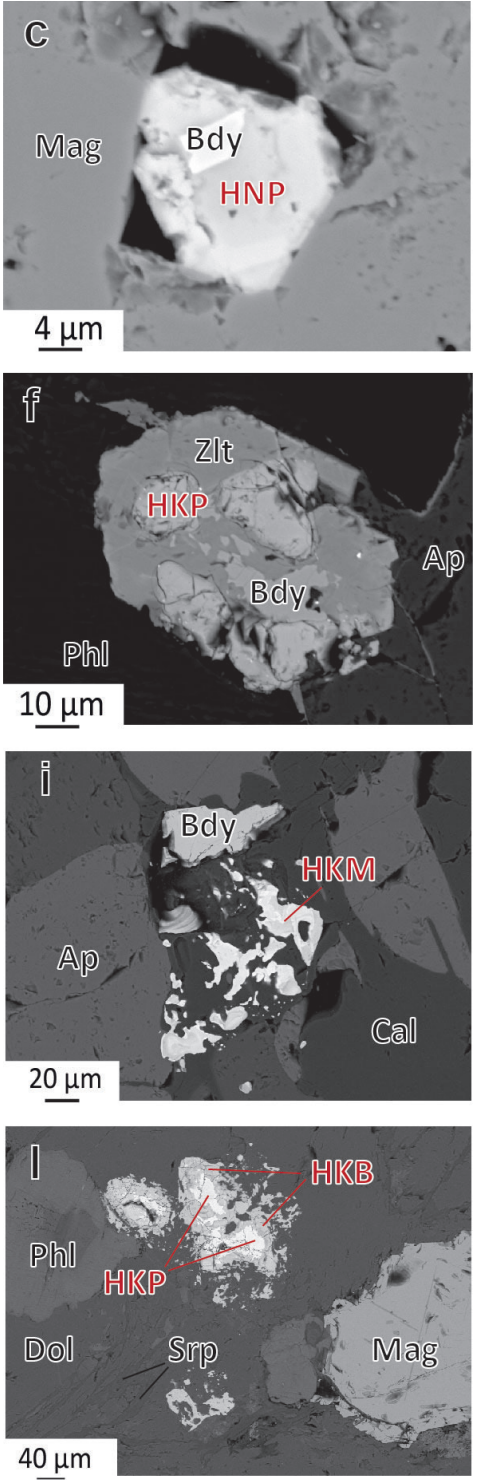

Рис. 3. Минералы супергруппы пирохлора.

a - оксикальциопирохлор (OCP) в Mag-Dol-Srp породе; b - гидроксикальциопирохлор (НСР) в жильном кальцитовом карбонатите; с - гидроксинатропирохлор (HNP) в Mag-Dol-Srp породе; d - гидроксикальциопирохлор (НСР) и фторкальциопирохлор (FCP) в Mag-Fo фоскорите; е - гидроксикенопирохлор (НКР) и гидроксинатропирохлор (HNP) во флогопитите; f - гидроксикенопирохлор (НКР) в доломитовом карбонатите; $\mathrm{g}$ - гидроксикальциомикролит (HCM) в Mag-Ap-Fo фоскорите; h - фторкальциомикролит (FCM) в Cal-MagAp-Fo фоскорите; i - гидроксикеномикролит (HKM) в Cal-Mag-Ap-Fo фоскорите; - гидроксикальциобетафит (HCB) в Mag-Ap-Fo фоскорите; k, 1 - гидроксикенобетафит (HKB) в Mag-Fo фоскорите. 
Практически все выделения пирохлора имеют зональное строение, обусловленное различиями химического состава. Наблюдается два типа зональности: первичная, сформированная в процессе кристаллизации минералов (кристаллы с четко выраженными зонами, рис. 3d), и вторичная, возникшая в процессе декатионизации и гидратации минерала (зоны сложной конфигурации, рис. 3е) или в результате обрастания первичного пирохлора более поздними генерациями (рис. 3e). Чаще всего оба типа зональности встречаются совместно. Зачастую микролиты и бетафиты соседствуют с пирохлорами в пределах одного шлифа и даже одного зерна, слагая в нем различные зоны (рис. 3 g, 1).

\section{Литература}

1. Кирнарский Ю.М., Афанасьев Б.В., Меньшиков Ю.П. Акцессорный ториевый бетафит из карбонатитов // Материалы по минералогии Кольского полуострова. Л. Наука. 1968. С. 258-264.

2. Осокин А.С. Акцессорная редкометальная минерализация карбонатитов одного из массивов щёлочноультраосновных пород (Кольский полуостров) / Минералогия и геохимия. Изд. ЛГУ. 1979. С. 27-38.

3. Стрельникова Л.А., Полежаева Л.И. Акцессорные минералы группы пирохлора из карбонатитов некоторых щёлочно-ультраосновных массивов / Вещественный состав щелочных интрузивных комплексов Кольского полуострова. Апатиты. КФАН СССР. 1981. С. 81-88.

4. Субботин В.В., Субботина Г.Ф. Минералы группы пирохлора в фоскоритах и карбонатитах Кольского полуострова // Вестник МГТУ. 2000. Т. 3. № 2. С. 273-284.

5. Atencio D., Andrade M.B., Christy A.G., Giere R., Kartashov P.M. The pyrochlore supergroup of minerals: nomenclature // The Canadian Mineralogist. 2010. V. 48. P. 673-698; doi: 10.3749/canmin.48.3.673.

6. Ivanyuk G.Yu, Yakovenchuk V.N., Pakhomovsky Ya.A. Kovdor. Laplandia Minerals, Apatity, 2002. 326 p.

7. Ivanyuk G.Yu., Yakovenchuk V.N., Panikorovskii T.L., Konoplyova N.G., Pakhomovsky Ya.A., Bazai A.V., Bocharov V.N., Krivovichev S.V. Hydroxynatropyrochlore, $(\mathrm{Na}, \mathrm{Ca}, \mathrm{Ce})_{2} \mathrm{Nb}_{2} \mathrm{O}_{6}(\mathrm{OH})$, a new member of the pyrochlore group from the Kovdor phoscorite-carbonatite pipe (Kola Peninsula, Russia) // Mineralogical Magazine. 2018 (in print).

8. Mikhailova J.A., Kalashnikov A.O., Sokharev V.A., Pakhomovsky Ya.A., Konopleva N.G., Yakovenchuk V.N., Bazai A.V., Goryainov P.M., Ivanyuk G.Yu. 3D mineralogical mapping of the Kovdor phoscorite-carbonatite complex (Russia) // Mineralium Deposita. 2016. V. 51 (1). P. 131-149. 